\title{
Indications of melt in near-surface ice-core stratigraphy: comparisons with passive-microwave melt signals over the Greenland ice sheet
}

\author{
Clinton M. Rowe, Mark R. Anderson, \\ Department of Geography and Snow and Ice Research Group, University of Nebraska-Lincoln, Lincoln, NE 68588, U.S.A. \\ Thomas L. Mote, \\ Department of Geography, University of Georgia, Athens, GA 30602, U.S.A. \\ KARL C. Kuivinen \\ Department of Geography and Snow and Ice Research Group, University of Nebraska-Lincoln, Lincoln, NE 68588, U.S.A.
}

\begin{abstract}
During the summer of 1993, a field program was conducted to collect several shallow firn cores from two locations in the southern region of the Greenland ice sheet. Stratigraphic evidence of melt from these cores was used for comparison with satellite-derived indications of melt.

The shallow firn cores were examined for stratigraphic evidence of past melt events and were sampled for oxygen-isotope analysis to delineate the annual accumulation layers in the snowpack. The relative intensity of each year's summer melt episode was compared to the corresponding melt frequency derived from microwave emissions. This comparison demonstrates that a linkage between the stratigraphic record and microwave data can be established. Both data sets indicate that there was less melt during the late 1970s and early 1980s than during the late 1980 s, in general agreement with climate observations.
\end{abstract}

\section{INTRODUCTION}

High-latitude regions are expected to be more sensitive to climatic change than are regions at middle and low latitudes, due to an enhanced greenhouse effect. Thus, much effort has been directed toward detecting climate changes in polar regions. Because of the paucity of climate stations in polar regions, proxy data are often utilized. Ice cores preserve a record of past climates in a variety of their physical characteristics, including stratigraphy, stable-isotope concentrations, microparticles and conductivity.

Passive-microwave remote sensing offers a means of detecting changes in the snow cover over large geographic areas. At microwave frequencies, the emissivity of dry snow increases dramatically with the addition of small amounts of liquid water, so that passive-microwave remote sensing can detect the onset, duration and cessation of snow melt. Because these data have been collected for only a relatively short period, their use in detecting climatic change is limited. However, satellite passive-microwave data do provide a means to monitor current and future melt conditions on the Greenland ice sheet.

\section{DATA AND METHODS}

\section{Shallow firn cores}

Shallow firn cores were obtained at two sites, Dye 2 $\left(66^{\circ} 29^{\prime} \mathrm{N}, 46^{\circ} 17^{\prime} \mathrm{W}, 2117 \mathrm{~m}\right.$ a.s.l. $)$ and South Cluster $\left(65^{\circ} 18^{\prime} \mathrm{N}, 45^{\circ} 50^{\prime} \mathrm{W}, 2442 \mathrm{~m}\right.$ a.s.l.), in southern Greenland (Fig. 1), using a lightweight, hand-powered auger. These cores were inspected and the position, thickness and character of all stratigraphic features (e.g. ice layers, ice wedges) were recorded. Each core was then divided every $5 \mathrm{~cm}$ along the length of the core into samples for density measurement and subsequent oxygen-isotope analysis.

Oxygen-isotope values are most often presented as standardized ratios $\left(\delta^{18} \mathrm{O}\right)$ of deviations of the proportion of ${ }^{18} \mathrm{O}$ from that of standard mean ocean water (SMOW defined as

$\delta^{18} \mathrm{O}=\frac{\left({ }^{18} \mathrm{O} /{ }^{16} \mathrm{O}\right)_{\text {sample }}-\left({ }^{18} \mathrm{O} /{ }^{16} \mathrm{O}\right)_{\text {SMOW }}}{\left({ }^{18} \mathrm{O} /{ }^{16} \mathrm{O}\right)_{\text {SMOW }}} \times 1000$.

A more negative value of $\delta^{18} \mathrm{O}$ indicates that the precipitation in the sample was formed at lower 


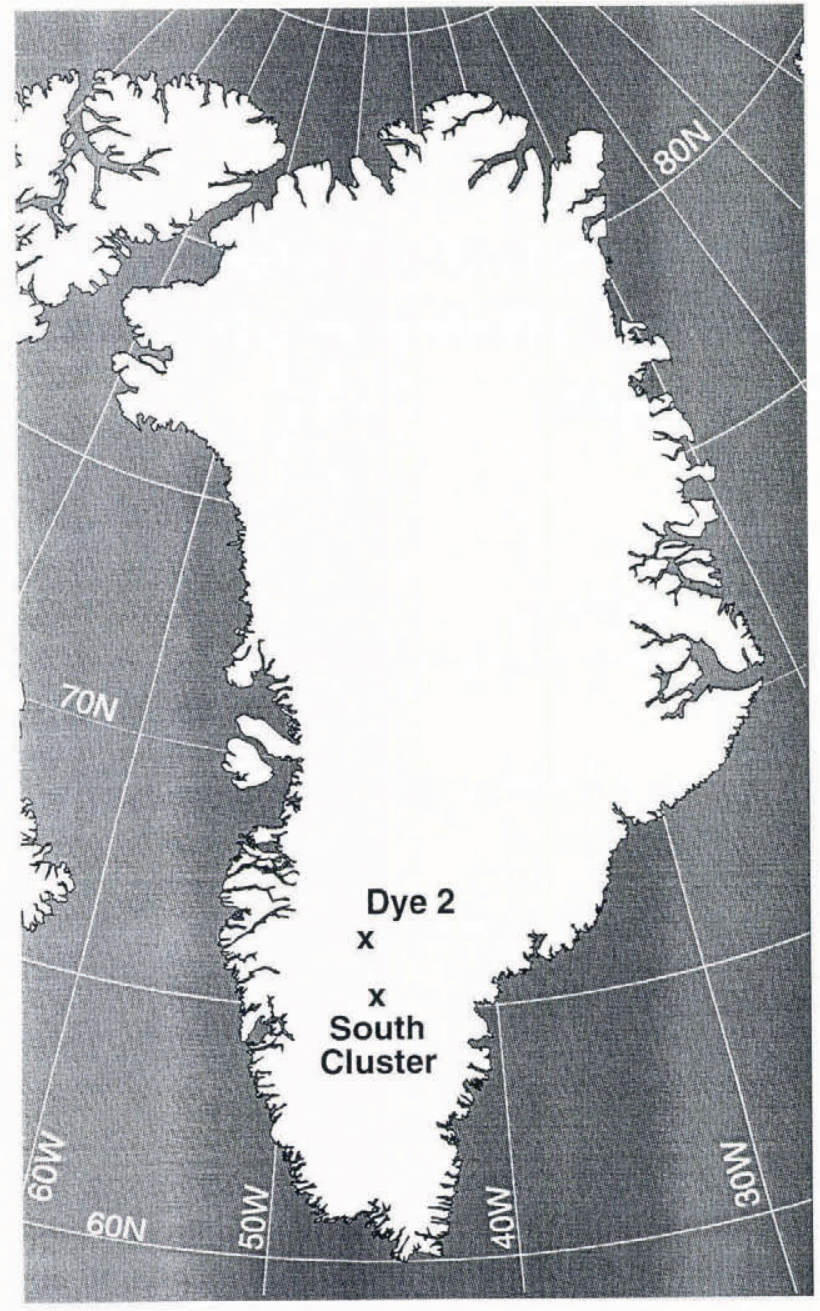

Fig.1. Location map of the two sites where shallow firm cores were obtained.

temperature (Dansgaard and others, 1973). Thus, $\delta^{18} \mathrm{O}$ can be used as a surrogate for air temperature.

As the coldest temperatures are to be expected during the winter, when no melt takes place, minima in the $\delta^{18} \mathrm{O}$ vs depth curve were used to delineate melt seasons in this study. Each core was then analyzed to give the thickness of each year's accumulation (Fig. 2).

\section{Passive-microwave data}

Determination of snowpack melt was made using data from two satellite microwave radiometers, the Scanning Multichannel Microwave Radiometer (SMMR) and the Special Sensor Microwave/Imager $(\mathrm{SSM} / \mathrm{I})$. These data were obtained from the U.S. National Snow and Ice Data Center (NSIDC) archive of daily brightness temperatures binned into a $25 \mathrm{~km} \times 25 \mathrm{~km}$ grid on a polar stereographic projection. The SMMR data are available on alternate days from October 1978 to August 1987 and the SSM/I data are available daily beginning in July 1987. Determination of which grid cells were undergoing surface melt was made using data from the $37 \mathrm{GHz}$ horizontal polarization channel of both sensors (Mote, 1994). Differences in view angle, radiometric resolution, calibration, and time and frequency of observations lead to a systematic difference between
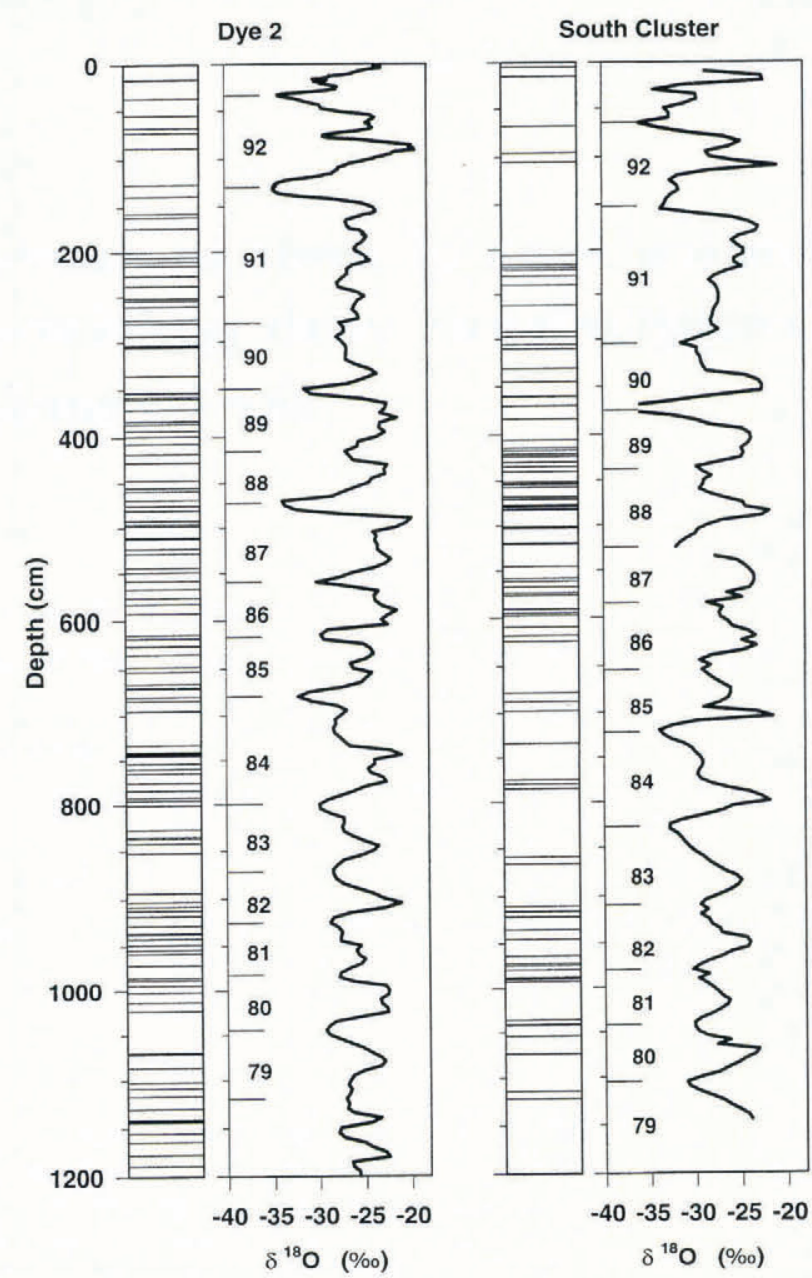

Fig. 2. Ice-feature stratigraphy and oxygen-isotope ratios for the firn cores from the Dye 2 and South Cluster sites. The horizontal bars mark the position and approximate thickness of all ice features observed in the core. Annual layering as derived from the oxygen-isotope ratios is indicated on the ${ }^{18} \mathrm{O}$ plot by the last two digits of the year.

the SMMR and SSM/I sensors, primarily due to the difference in calibration of the two sensors (Jezek and others, 1991). A linear regression of the brightness temperatures over the dry-snow region of the ice sheet for the period during which both sensors were operating (10 July-20 August 1987) allows the systematic difference between sensors to be removed (Mote, 1994). All SMMR brightness temperatures used in this study were converted to equivalent SSM/I brightness temperatures based on this regression.

At frequencies greater than $10 \mathrm{GHz}$, the brightness temperature $\left(T_{\mathrm{B}}\right)$ of snow increases monotonically with increasing volumetric liquid-water content $\left(m_{\mathrm{v}}\right)$, for $m_{\mathrm{v}}$ less than 6\% (Stiles and Ulaby, 1980). The $T_{\mathrm{B}}$ is also dependent on the thermometric temperature of the snow, but the increase in $T_{\mathrm{B}}$ due to even a small addition of liquid water is much greater than could occur from an increase in thermometric temperature. Thus, a unique $T_{\mathrm{B}}$ threshold value can be selected for a given $m_{\mathrm{v}}$ indicative of the onset of melting (Mote, 1994).

A simple microwave-emission model was used to estimate the $37 \mathrm{GHz}$, horizontally polarized $T_{\mathrm{B}}$ associated with $1 \%$ liquid water content in the 
snowpack. The $1 \%$ value was chosen because the $T_{\mathrm{B}}$ of the snowpack typically shows the greatest increase as $m_{\mathrm{v}}$ increases from $0.5 \%$ to $1 \%$ (Stiles and Ulaby, 1980). A semi-empirical approach was used in which the scattering properties of the snowpack were estimated from the brightness temperatures observed before the onset of melt (Mote and Anderson, in press). The dielectric constant of the ice-air-water mixture under melt conditions was calculated through the use of a dielectric mixing model described by Tiuri and Schultz (1980). The change in the bulk dielectric as liquid water forms in the snowpack results in an increased emissivity and, therefore, a higher brightness temperature. A simplified version of the radiative-transfer equation shown by Ulaby and Stiles (1980) was then used to estimate a brightness temperature associated with melt for each grid cell on the ice sheet.

A threshold approach (Mote, 1994) was used to identify the occurrence of melt in each grid cell over the ice sheet for each day of available data. On a given day, if the observed $37 \mathrm{GHz}$, horizontally polarized $T_{\mathrm{B}}$ from a grid cell exceeded the modeled threshold value, that location is considered to have experienced melt. Time series of melt occurrence were extracted for the grid cells containing the Dye 2 and South Cluster sites for further analysis.

\section{DISCUSSION}

Visual inspection of the number and location of melt features identified in the cores as a function of depth (Fig. 2) reveals that, prior to 1991, melt features are more common in the upper (more recent) parts of the cores than in the lower (less recent) parts. This is especially true for the South Cluster core. For example, 1983 and 1984 show very few melt indications compared to 1988 and 1989, when numerous melt features were observed in the core. Not only are there more ice features, but the thickness of the layers is also greater. The apparent increase in the frequency of melt features begins in 1985 at Dye 2 and 1986 at South Cluster. This corresponds well to the increase in mean melt extent on the southwest part of the ice sheet since 1986 identified by Mote and Anderson (in press).

A more direct, quantitative comparison of the microwave melt frequency and the melt features in the cores is difficult to make. Perhaps ideally, the number of melt features observed in an annual layer of the core would correspond to the total number of melt events identified with the microwave data, where a melt event is defined as one or more consecutive days for which the brightness temperature exceeded the melt threshold (Table 1). However, melt events cannot be determined unambiguously from the SMMR record as observations were made only on alternate days. As a result, two consecutive observations of melt in the SMMR data could correspond to a single $3-5 \mathrm{~d}$ melt event or to two 1-2d events separated by an unobserved day with no melt. Furthermore, because of the complex flow regime of meltwater as it percolates into the snowpack, there is not necessarily a one-to-one relationship between melt events and the number of melt features. For example, a single melt event, especially one producing a relatively large amount of meltwater, could result in multiple ice layers as liquid water spreads out along horizontal strata in the snow. Conversely, successive melt events may not produce separate ice features in the snowpack, as

Table 1. Microwave-derived melt events and frequencies and number of ice features in each annual layer for the Dye 2 and South Cluster sites

\begin{tabular}{|c|c|c|c|c|c|c|}
\hline \multirow[b]{2}{*}{ Year } & \multicolumn{3}{|c|}{ Dye 2} & \multicolumn{3}{|c|}{ South Cluster } \\
\hline & $\begin{array}{l}\text { Melt } \\
\text { events }^{*}\end{array}$ & $\begin{array}{c}\text { Melt } \\
\text { frequency } \\
\%\end{array}$ & $\begin{array}{c}\text { Ice } \\
\text { features }\end{array}$ & $\begin{array}{c}\text { Melt } \\
\text { events }\end{array}$ & $\begin{array}{c}\text { Melt } \\
\text { frequency } \\
\%\end{array}$ & $\begin{array}{c}\text { Ice } \\
\text { features }\end{array}$ \\
\hline 1991 & 11 & 19.7 & 3 & 4 & 8.6 & 5 \\
\hline 1990 & 7 & 10.2 & 3 & 5 & 5.9 & 5 \\
\hline 1989 & 3 & 11.5 & 4 & 3 & 7.0 & 6 \\
\hline 1988 & 5 & 21.7 & 5 & 4 & 5.2 & 11 \\
\hline 1987 & & 15.1 & 8 & - & 6.9 & 6 \\
\hline 1986 & - & 12.9 & 4 & - & 8.1 & 6 \\
\hline 1985 & - & 9.8 & 2 & & 6.6 & 2 \\
\hline 1984 & - & 7.1 & 9 & - & 5.4 & 3 \\
\hline 1983 & - & 6.5 & 2 & - & 4.8 & 2 \\
\hline 1982 & - & 5.4 & 2 & - & 1.8 & 4 \\
\hline 1981 & - & 9.7 & 3 & & 8.1 & 4 \\
\hline 1980 & - & 0.0 & 2 & - & 1.6 & 2 \\
\hline 1979 & - & 6.5 & 1 & & 4.8 & 2 \\
\hline
\end{tabular}

\footnotetext{
* The number of melt events cannot be computed for that part of the time series containing SMMR data (see text for explanation).
} 
meltwater from a subsequent event may simply refreeze to the previous ice layer. Therefore, it is necessary to standardize the microwave-derived melt occurrences and snowpack-melt features on a seasonal basis for comparison.

As a first attempt at this, the total thickness of all ice features in each annual layer in the core was computed and compared to the annual microwave-derived frequency of melt for the grid cell containing each site (Fig. 3). For this comparison, the melt frequency is expressed as the percentage of days between 1 May and 31 August of a given year for which melt conditions were identified in that cell. A percentage of days is used rather than the raw frequency to account for the difference in the number of days with available data for each year. Half of the maximum thickness was used for ice features that did not occupy the entire core diameter (e.g. lenses). This technique makes the assumption that liquid water produced during a melt season does not penetrate very far into the snowpack before refreezing and, thus, contributes to the ice volume only for the

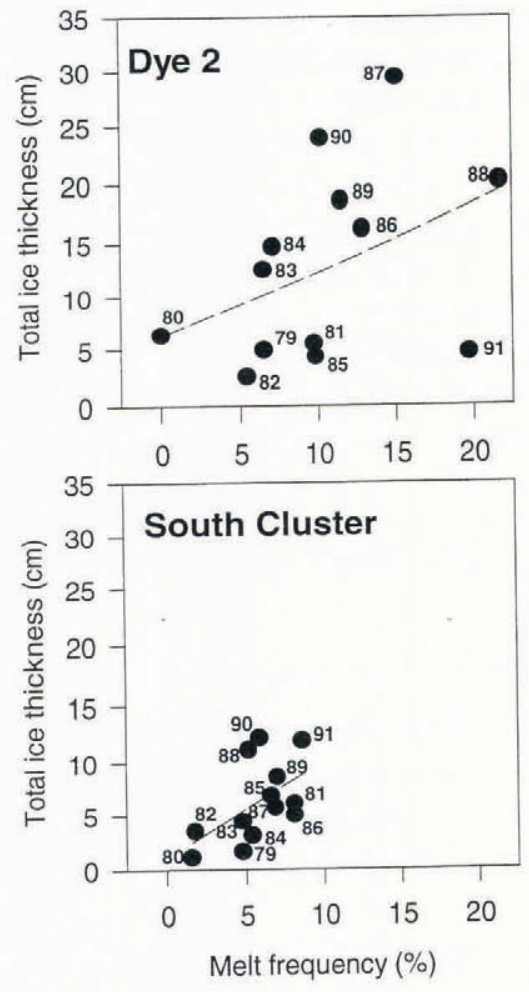

Fig. 3. Total ice-feature thickness in each annual accumulation layer versus the microwave-derived melt frequency for that year for the Dye 2 and South Cluster sites. Each data pair is identified by the last two digits of the year it represents.

year during which the melt took place. During the 1993 field season at Dye 2, meltwater penetrated only about $20 \mathrm{~cm}$ before refreezing into a nearly continuous ice layer.

For Dye 2, there seems to be a clear relationship between total ice-feature thickness in the annual layer and melt frequency, with two identifiable clusters of data: a low-frequency/low-ice cluster and a high-frequency/ high-ice cluster. Upon closer inspection, these two clusters are distinct temporally, with the low/low cluster comprising the years 1979-85 and the high/high cluster comprising 1986-90. At South Cluster, the relationship between these variables is not as strong and there is no clear separation of years into groups. The low incidence of melt at this site, and on the South Dome generally (Mote, 1994), likely results in a low signal/noise ratio for the microwave-derived melt-frequency time series. This may be the reason for the less distinct separation of clusters in the data for this site. Melt-frequency values for locations at higher elevation, where melt is relatively rare, must be used with caution. However, the slope of the regression line, although not significant due to the small number of data values, is about the same for the two sites, lending some credibility to the relationship.

The last year with microwave data available, 1991, is an outlier at Dye 2, with a high frequency of melt but a low ice volume. Further inspection of the $\delta^{18} \mathrm{O}$-derived annual layers reveals that, for both cores, the 1991 layer is approximately twice as thick as the other annual layers. A possible explanation for this is an increased number of summer storms bringing additional snowfall and reducing the time for thick ice features to develop during any one melt event. However, it must be remembered that the microwave signal yields the frequency of melt events, not the intensity of melt, and that more frequent melt does not always lead to greater total melt.

\section{SUMMARY AND CONGLUSIONS}

Shallow firn cores were obtained from the Dye 2 and South Cluster sites on the Greenland ice sheet during summer 1993. Oxygen-isotope analysis was performed to delineate annual accumulation layers. Within each annual layer, the total thickness of ice layers was obtained from the core stratigraphy as an indication of the relative amount of snow melt for that year. Using the $37 \mathrm{GHz}$ data from two satellite microwave radiometers, the occurrence of snow melt was identified using a threshold technique based on the increased emissivity caused by the formation of liquid water in the snowpack. Seasonal melt frequencies were determined for the two locations for each year from 1979 to 1991. Comparisons were then made between the two melt proxy-data sets.

Both the microwave-derived melt frequencies and the ice thicknesses obtained from the shallow firn cores show that the late 1970s and early 1980s had less melt than the late 1980s. Thus, the microwave-derived melt frequencies appear to represent a viable method of monitoring snowpack melt on the Greenland ice sheet. Continued monitoring of snow melt combined with measurements of accumulation and runoff will provide the data necessary for a better understanding of the mass balance of the ice sheet.

\section{ACKNOWLEDGEMENTS}

This research was funded by National Aeronautics and Space Administration grant NAGW-1266 and training grant NGT-30127. The authors thank R. H. Thomas of 
NASA and K. C. Jezek of Ohio State University for their assistance in obtaining the South Cluster core, and H. B. Clausen of the University of Copenhagen for the oxygenisotope analysis.

\section{REFERENCES}

Dansgaard, W., S. J. Johnsen, H. B. Clausen and N. Gundestrup. 1973. Stable isotope glaciology. Medd. Gronl., 197(2).

Jezek, K. C. and 6 others. 1991. Comparison between SSMR and SSM/I passive microwave data collected over the Antarctic ice sheet. Byrd Polar Research Center. Technical Report 91-03.

Mote, T. L. 1994. Variations in passive microwave measurements of melt on the Greenland ice sheet and associated Northern Hemisphere atmospheric circulation. Ph.D. dissertation, University of Nebraska Lincoln.

Mote, T. L. and M. R. Anderson. 1995. Variations in snowpack melt on the Greenland ice sheet based on passive-microwave measurements. J. Glaciol., 41 (137), $51-60$

Stiles, W. H. and F. T. Ulaby. 1980. The active and passive microwave response to snow parameters. 1. Wetness. 7. Geophys. Res., 85 C2 . $1037-1044$.

Tiuri, M. and H. Schultz. 1980. Theoretical and experimental studies of microwave radiation from a natural snowfield. In Rango, A.. ed. Microwave Remote Sensing of Snowpack Properties. Proceedings of a Workshop ... Fort Collins, Colorado ... 1980. Washington, DC, National Aeronautic and Space Administration, 225-234. Conference Publication 2153.

Ulaby, F.T. and W.H. Stiles. 1980. The active and passive microwave response to snow parameters. 2. Water equivalent of dry snow. $y$ Geophys, Res., 85 C2 , 1045-1049. 